\title{
Caracterização de um isolado do Sugarcane mosaic virus que quebra a resistência de variedades comerciais de cana-de-açúcar
}

\author{
Marcos C. Gonçalves ${ }^{1}$, Amaury S. Santos ${ }^{1}$, Ivan G. Maia ${ }^{2}$, César M. Chagas ${ }^{1}$ \& Ricardo Harakava $^{1}$ \\ ${ }^{1}$ Instituto Biológico, Centro de Pesquisa e Desenvolvimento em Sanidade Vegetal, Av. Conselheiro Rodrigues Alves 1252, \\ CEP 04014-002, São Paulo, SP, e-mail: mcgon@biologico.sp.gov.br; ${ }^{2}$ Universidade Estadual Paulista, \\ Campus de Botucatu, IB, Departamento de Genética, CEP 18618-000, Botucatu, SP
}

Autor para correspondência: Marcos C. Gonçalves

GONÇALVES, M.C., SANTOS, A.S., MAIA, I.G., CHAGAS, C.M. \& HARAKAVA, R. Caracterização de um isolado do Sugarcane mosaic virus que quebra a resistência de variedades comerciais de cana-de-açúcar. Fitopatologia Brasileira 32:032-039. 2007.

\begin{abstract}
RESUMO
Os vírus pertencentes ao subgrupo do Sugarcane mosaic virus (SCMV, gênero Potyvirus, família Potyviridae) infectam e causam mosaico em diferentes espécies botânicas da subfamília Panicoideae (família Poaceae), porém apenas o SCMV e o Sorghum mosaic virus (SrMV) infectam naturalmente cana-de-açúcar. No Brasil, a espécie SCMV parece ser o único agente causal da doença. Embora a maioria das variedades comerciais de cana-de-açúcar seja considerada resistente ou tolerante ao SCMV, relatos de incidência de mosaico em tais variedades têm ocorrido no campo. Amostras com sintomas, de diversos clones e variedades, foram coletadas em campos experimentais e comerciais de cana-de-açúcar. Dentre as variedades, a RB72-454, uma das mais plantadas no país e considerada resistente à doença, também apresentou plantas com sintomas de mosaico. As amostras foram testadas por DAS-ELISA, com anti-soros policlonais para as espécies SCMV, Johnsongrass mosaic virus (JGMV) e Maize dwarf mosaic virus (MDMV), apresentando resultados negativos. Porém, sintomas de mosaico foram observados em mudas de sorgo "Rio" e "TX2786" quando inoculadas mecanicamente com os isolados, indicando tratar-se de infecção pelo SCMV. RNA total foi extraído das folhas de cana e submetido a RT-PCR com oligonucleotídeos específicos para SCMV e SrMV. Fragmentos específicos de aproximadamente 880 pares de bases foram amplificados com os oligonucleotídeos para o SCMV, confirmando os resultados da inoculação mecânica. Os produtos de PCR foram clonados e seqüenciados. Um dos isolados de SCMV encontrado constitui uma nova estirpe, mais severa, capaz de infectar plantas da variedade RB72-454 e de outras variedades, consideradas tolerantes, no campo.
\end{abstract}

Palavras-chave adicionais: Potyviridae, mosaico da cana, Sugarcane mosaic virus subgroup.

\begin{abstract}
Characterization of an isolate of Sugarcane mosaic virus breaking down resistance of commercial sugarcane varieties

Viruses in the Sugarcane mosaic virus (SCMV, genus Potyvirus, family Potyviridae), subgroup cause mosaic in different botanical species in the subfamily Panicoideae (family Poaceae). However, only SCMV and Sorghum mosaic virus (SrMV) naturally infect sugarcane. In Brazil, SCMV seems to be the only causal agent of mosaic in sugarcane. Most sugarcane cultivars are believed to be resistant to mosaic, although new cases have been reported in the field. Symptomatic samples, from several clones and cultivars, were collected in sugarcane crops. Among these cultivars, RB72-454, one of the most grown in Brazil, and considered resistant, showed plants with mosaic symptoms. Samples were tested by DASELISA with antisera to SCMV, Johnsongrass mosaic virus (JGMV) and Maize dwarf mosaic virus (MDMV), showing negative results. However, sorghum "Rio" and "TX2786" showed mosaic symptoms when mechanically inoculated with the viral isolates, indicating infection by SCMV. Total RNA was extracted and submitted to amplification with specific primers to SCMV and SrMV in RT-PCR. Specific bands with ca. $880 \mathrm{bp}$ were amplified with the SCMV-specific primer pair, corroborating results from mechanical inoculation. PCR products were cloned and sequenced. One of the SCMV isolates comprises a new and more severe strain capable of infecting RB72-454 and other tolerant cultivars in the field.
\end{abstract}

Additional keywords: Potyviridae, sugarcane mosaic, Sugarcane mosaic virus subgroup.

\section{INTRODUÇÃO}

No Brasil, entre as principais viroses incidentes na cultura da cana-de-açúcar está o mosaico, historicamente e potencialmente uma das doenças mais importantes dessa cultura. Diversas epidemias da doença ocorreram no país na década de 1920, sendo controladas pela substituição das variedades suscetíveis por híbridos resistentes.
Posteriormente, devido à sua suposta erradicação, variedades suscetíveis voltaram a ser plantadas, ocasionando novos ciclos epidêmicos da doença.

O mosaico pode ser causado por um subgrupo de quatro espécies distintas de Potyvirus que infectam diferentes poáceas: Sugarcane mosaic virus (SCMV), espécie que dá nome ao complexo viral do SCMV; Maize dwarf mosaic virus (MDMV); Johnsongrass mosaic virus 
(JGMV); e Sorghum mosaic virus (SrMV) (McKern et al., 1991; Lesemann et al., 1992; Shukla et al., 1992a). Recentemente, a espécie Zea mosaic virus (ZeMV), isolada de milho, foi proposta como um novo membro do subgrupo (Seifers et al., 2000). Contudo, apenas as espécies SCMV e SrMV infectam a cana-de-açúcar em condições naturais. No Brasil, apenas a espécie SCMV é encontrada infectando naturalmente cana-de-açúcar (Gonçalves et al., 2004).

Os vírus do subgrupo do SCMV e suas diversas estirpes pertencem ao gênero Potyvirus, família Potyviridae (Fauquet et al., 2005) e são transmitidos por várias espécies de afídeos, dentre as quais Rhopalosiphum maidis e Schizaphis graminum (Teakle et al., 1989), comumente encontrados em diversas culturas no Brasil. A transmissão é do tipo não persistente e os períodos de acesso de aquisição e transmissão duram de poucos segundos a minutos; por sua vez, o período de retenção pode durar até algumas horas, como no caso do SCMVMDB (Shukla et al., 1994). Os sintomas iniciais de infecção consistem em pontos cloróticos com distribuição linear no meio ou mais comumente na base das folhas, que evoluem para áreas alongadas formando um mosaico típico, o qual pode aumentar de severidade com a idade da folha. $\mathrm{O}$ crescimento das plantas pode ser acentuadamente reduzido, conforme a espécie e estirpe do vírus e a variedade de cana, principalmente quando a infecção ocorre nos estágios iniciais de desenvolvimento. Ocasionalmente, em variedades altamente suscetíveis, podem ocorrer riscas e estrias nos colmos e encurtamento dos entrenós.

Atualmente, a doença está controlada no país com o uso de variedades resistentes, porém, freqüentemente observam-se plantas sintomáticas durante a avaliação de novos clones de cana-de-açúcar visando o melhoramento genético e, ocasionalmente, em viveiros de mudas e plantios comerciais. Apesar desse fato, o mosaico não tem ocasionado perdas de grandes proporções, devido à seleção de variedades resistentes, associada à prática do "roguing" nos plantios comerciais. No entanto, esse vírus incide sobre outras gramíneas, dentre as quais o milho, Zea mays (Costa et al., 1971) e o sorgo, Sorghum bicolor (Pinto, 1980; 1984). O grande aumento da área plantada de milho no país nos últimos anos, associado ao cultivo na safrinha (milho semeado entre janeiro e março), têm prolongado a permanência da cultura no campo contribuindo para a maior incidência do mosaico e a manutenção da fonte de inóculo (Dudienas et al., 1997; Fernandes \& Oliveira, 1997; Waquil et al., 1996). Em conseqüência, amplia-se a possibilidade de que novas estirpes do SCMV estejam se disseminando no campo.

Este trabalho relata a ocorrência e a caracterização de uma nova estirpe do SCMV que causa sintomas particularmente severos em novos clones de cana-deaçúcar (Figura 1) e infecta naturalmente a variedade RB72-454, uma das mais plantadas no território nacional e considerada resistente ao mosaico.

\section{MATERIAL E MÉTODOS}

\section{Coleta de amostras e indexação biológica}

Amostras foliares e de colmos de clones e variedades de cana-de-açúcar com sintomas de mosaico foram coletadas em campos experimentais e comerciais no estado de São Paulo. Os isolados foram divididos com base em (i) regiões de coleta; (ii) genótipo da hospedeira e (iii) tipos de sintomas nas hospedeiras. $\mathrm{O}$ material coletado foi armazenado a -20 ${ }^{\circ} \mathrm{C}$ e/ou, plantado em vasos mantidos em casa-de-vegetação. Três isolados foram estudados nesse trabalho: RIB-1, PIR-2 e JAU-1, provenientes de amostras coletadas nos municípios paulistas de Guaíra, Piracicaba e Jaú, respectivamente.

Os isolados virais foram inoculados nas cultivares diferenciais de sorgo "Rio" e "TX 2786", e em plantas de aveia (Avena sativa) (Shukla et al., 1994; Tosic et al., 1990). As inoculações foram realizadas com alíquotas de folhas das plantas infectadas, trituradas em nitrogênio líquido e diluídas na proporção 1:10 em tampão fosfato de sódio 0,01 M, pH 7,2, com 0,1\% de sulfito de sódio. Dez plantas de cada espécie e/ou cultivar de indicadora foram inoculadas no estádio de sete dias após a emergência, e uma planta adicional deixada como controle, sem inoculação. Três repetições deste experimento foram realizadas no decorrer dos meses de novembro a junho. Todas as plantas foram mantidas em casas de vegetação com tela de proteção antiafídeo, e os sintomas foram monitorados semanalmente.

\section{Análises serológicas}

Os isolados coletados foram submetidos à análise por DAS-ELISA com anti-soros policlonais (AGDIA Inc., Elkhart, Indiana, USA) para as espécies SCMV, JGMV e MDMV do subgrupo do SCMV, utilizando-se controles positivos e negativos para cada espécie de vírus adquiridos da mesma empresa. $O$ procedimento para as análises e os tampões utilizados seguiram as recomendações do fabricante.

As amostras também foram submetidas ao teste de PTA-ELISA com um anti-soro policlonal produzido a partir de um "pool" de isolados americanos do SCMV, gentilmente fornecido pelo Dr. T. Erik Mirkov (Texas A\&M University, USA). O procedimento foi realizado conforme descrito por Koenig \& Paul (1982).

Para os dois testes, DAS e PTA-ELISA, as leituras de absorbância foram feitas a $405 \mathrm{~nm}$ e consideradas positivas as amostras que apresentaram médias dos valores de absorbância, de três réplicas, superiores a três vezes a média do controle negativo.

\section{Microscopia Eletrônica}

Amostras de folhas infectadas com o isolado RIB-1 foram analisadas por microscopia eletrônica de transmissão (MET). Para observações em contrastação negativa do extrato foliar e também in situ empregou-se procedimento previamente descrito (Chagas et al., 1993). As observações foram efetuadas em microscópio eletrônico Philips EM208. 


\section{RT-PCR}

Um oligo(dT) de 17 nucleotídeos, ancorado na sua extremidade $3^{\prime}\left(\mathrm{dT}_{17} \mathrm{~V}\right)$ foi utilizado para obtenção dos cDNAs. As reações de transcrição reversa (RT) foram realizadas com o kit cMaster Rtplus (Eppendorf - Netheler, Hamburg, Germany) aplicando-se $2 \mu \mathrm{g}$ de RNA total extraído das plantas infectadas, em combinação com $5 \mu \mathrm{M}$ do oligonucleotídeo $\mathrm{dT}_{17} \mathrm{~V}$, previamente incubados a 70 ${ }^{\circ} \mathrm{C}$ por 10 minutos. Os oligonucleotídeos senso SCMVF4 (Alegria et al., 2003) e SrMVF3 (Yang \& Mirkov, 1999) e os oligonucleotídeos anti-senso SCMVR3 e SrMVF3 (Yang \& Mirkov, 1997) foram usados para amplificar regiões do genoma correspondentes à capa protéica $(\mathrm{CP})$ das espécies SCMV e SrMV, respectivamente. O cDNA proveniente da reação de RT foi amplificado com 2 combinações de oligonucleotídeos: (i) $5 \mu \mathrm{M}$ do oligonucleotídeo degenerado SCMVF4 e $1 \mu \mathrm{M}$ do oligonucleotídeo SCMVF3; (ii) $1 \mu \mathrm{M}$ dos oligonucleotídeos SrMVF3 e SrMVR3. As reações de PCR foram feitas com $2 \mu \mathrm{L}$ do produto da RT por reação, seguindo as instruções do kit cMaster Rtplus. As amostras foram levadas para um termociclador MJ-Research PTC200 onde, após a desnaturação inicial a $94{ }^{\circ} \mathrm{C}$ por 3 minutos, a amplificação foi feita com 35 ciclos de $94{ }^{\circ} \mathrm{C}$ por 1 minuto, $54{ }^{\circ} \mathrm{C}$ por 2 minutos, $72{ }^{\circ} \mathrm{C}$ por 3 minutos, seguidos por uma extensão final a $72{ }^{\circ} \mathrm{C}$ por 10 minutos. Os produtos de PCR foram analisados por eletroforese em gel de agarose $1,2 \%$, preparado em tampão TAE, $\mathrm{pH} 8,0$, corado com brometo de etídeo e observado sob luz UV.

\section{Clonagem e seqüenciamento}

As bandas selecionadas foram recortadas do gel e pesadas para purificação do DNA com o kit Rapid Gel Extraction (GIBCO, BRL - Life Technologies, New York, USA). Os fragmentos de DNA foram clonados usando o pGEM-T Easy Vector System (Promega) e pCR2.1-Topo (Invitrogen) em Escherichia coli DH5 $\alpha$. Após a seleção dos clones recombinantes em meio contendo antibiótico, a presença dos fragmentos clonados nos respectivos vetores foi confirmada por digestão com a enzima de restrição EcoRI e posterior eletroforese em gel de agarose $1 \%$. Os fragmentos de DNA eluídos foram precipitados com etanol absoluto e acetato de sódio $3 \mathrm{M}, \mathrm{pH} 5,1$. Os sedimentos obtidos foram ressuspendidos em tampão TE $\mathrm{pH}$ 8,0 e purificados em coluna Qiaquick (Qiagen). As seqüências de nucleotídeos foram determinadas usando o kit "Big Dye" (Applied Biosystems Inc.) segundo protocolo do fabricante e um seqüenciador automático modelo 3100 (Applied Biosystems Inc.). Foram realizadas três reações de seqüenciamento com cada oligonucleotídeo para a confirmação das seqüências obtidas. As seqüências de nucleotídeos e as deduzidas de aminoácidos foram analisadas e alinhadas com o software "Bio Edit - Sequence Alignment Editor" (Hall, 1999) e os consensos submetidos ao algoritmo BLAST do "National Center for Biotechnology Information", NCBI (www.ncbi. nlm.nih.gov) para comparação às seqüências homólogas depositadas no "GenBank". Alinhamentos múltiplos foram realizados com o software ClustalW e o grau de identidade de nucleotídeos foi determinado com o BioEdit.

\section{RESULTADOS}

\section{Indexação biológica dos isolados}

Os três isolados inoculados provocaram mosaico típico, com diferentes intensidades, nos cultivares de sorgo Rio e TX 2786 (Figura 2A). Por sua vez, o isolado obtido a partir plantas da variedade RB72-454, denominado RIB1, que apresentava sintomas particularmente severos em cana (Figura 1), também provocou mosaico mais intenso nas plantas de sorgo "Rio" e, posteriormente, algumas das folhas adquiriram uma tonalidade avermelhada seguida por eventual necrose do tecido (Figura 2B). As plantas de aveia inoculadas com os três isolados selecionados não apresentaram quaisquer sintomas de infecção.

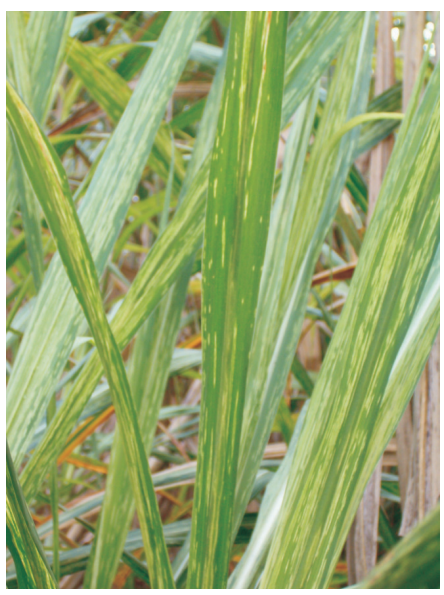

FIG. 1 - Planta de cana-de-açúcar do clone SP95-3224 infectada com o isolado de SCMV RIB-1, apresentando sintomas severos de mosaico.
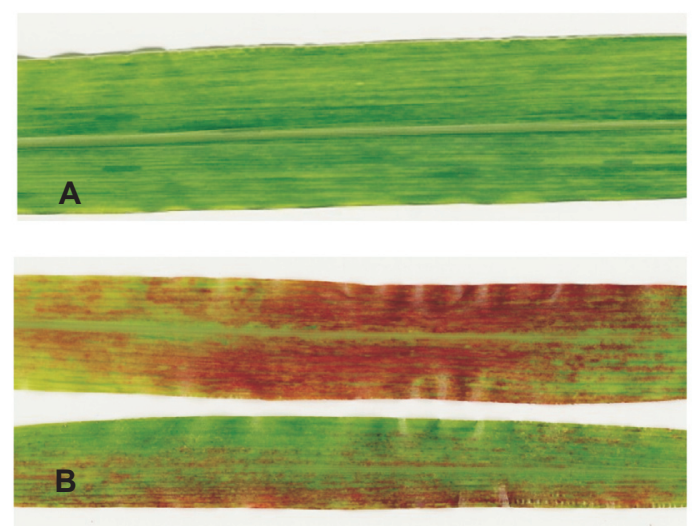

FIG. 2 - A. Folha de planta de sorgo "Rio" inoculada com o isolado de SCMV JAU-1, apresentando sintomas de mosaico; B. Folhas de planta de sorgo "Rio" inoculada com o isolado RIB-1, apresentando sintomas severos de mosaico, avermelhamento e necrose. 


\section{Análises serológicas}

Os três isolados apresentaram resultado negativo em DAS-ELISA com os anti-soros para as espécies MDMV e JGMV. Apenas os isolados PIR-2 e JAU-1 reagiram positivamente em DAS-ELISA com o anti-soro para a espécie SCMV. Por sua vez, os três isolados apresentaram resultado positivo em PTA-ELISA com o anti-soro policlonal proveniente do Texas.

\section{Microscopia Eletrônica}

As amostras de extratos foliares contrastadas negativamente apresentaram partículas virais alongadas e flexuosas com tamanho variando entre 756 e $801 \mathrm{~nm}$ (Figura 3A), com a maior freqüência de partículas de aproximadamente $780 \mathrm{~nm}$. As seções ultrafinas apresentaram partículas virais no citoplasma semelhantes às observadas nos contrastes negativos, além de inclusões citoplasmáticas típicas da família Potyviridae, incluindo cataventos, tubos e agregados laminares e "scrolls" (Figura 3B). Não foi notada qualquer outra alteração citopática que pudesse ser atribuída ao vírus.

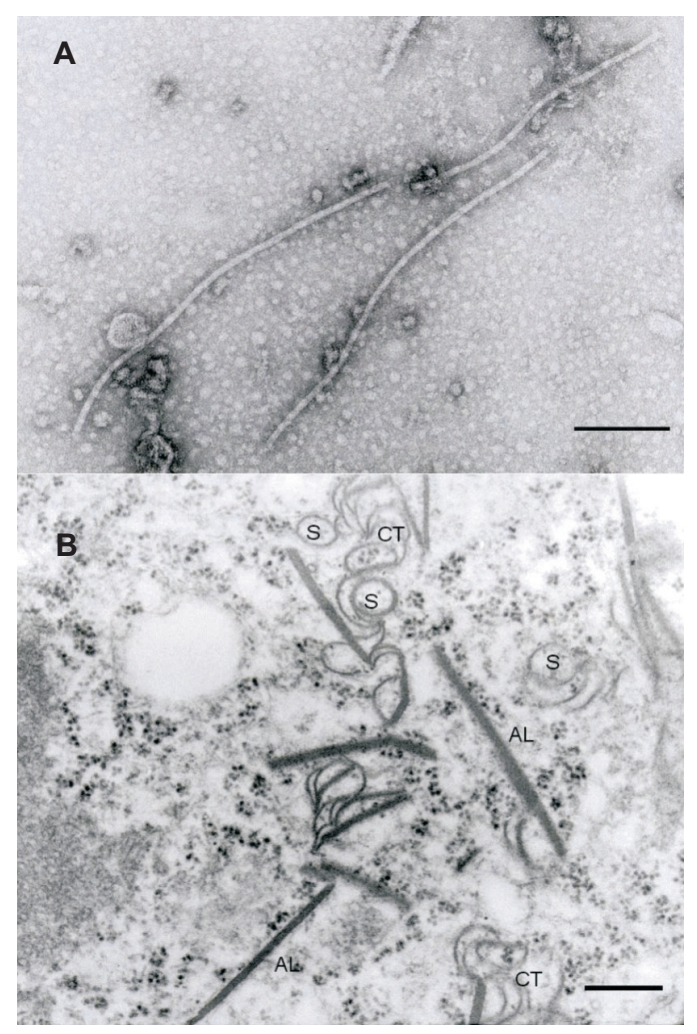

FIG. 3 - A. Micrografia eletrônica de transmissão de extrato foliar de cana-de-açúcar infectada com o isolado de SCMV RIB1 , mostrando partículas virais alongadas e flexuosas, contrastadas negativamente com acetato de uranila $2 \%$. Barra de escala $=200$ nm; B. Micrografia eletrônica de transmissão de cortes ultrafinos de folhas de cana-de-açúcar infectada com o isolado de SCMV RIB1, apresentando inclusões cilíndricas citoplasmáticas: cataventos (CT), agregados laminares (AL), "scrolls" (S). Barra de escala = $300 \mathrm{~nm}$.

\section{Amplificação por RT-PCR e análise de seqüências}

A análise eletroforética revelou a presença de bandas específicas de $888 \mathrm{pb}$ para os isolados testados, amplificadas unicamente com o par de oligonucleotídeos SCMVF4 e SCMVR3 (Figura 4). As seqüências de nucleotídeos obtidas, correspondentes à região codificadora da proteína capsidial dos três isolados brasileiros do SCMV de cana-de-açúcar, RIB-1, JAU-1 e PIR-2, foram depositadas no "GenBank" sob os números de acesso AY819716, AY819717 e AY819718, respectivamente. A porcentagem de identidade das seqüências de nucleotídeos da proteína capsidial entre o isolado RIB-1 e os demais isolados brasileiros e entre outros 97 isolados do SCMV depositados no GenBank foi de 96 a $97 \%$ e de 92 a 96\%, respectivamente. As seqüências deduzidas de aminoácidos da proteína capsidial dos três isolados brasileiros e as de outros membros do subgrupo do SCMV e do gênero Potyvirus foram utilizadas para a construção de um filograma (Figura 5), que ilustra a posição do isolado RIB-1 em relação aos demais isolados brasileiros, a oito isolados de SCMV de diferentes regiões geográficas, e às espécies MDMV, SrMV e JGMV. O isolado RIB-1 agrupa-se com os outros dois isolados brasileiros de SCMV, PIR-2 e JAU-1, e com isolados provenientes da Austrália (Brisbane-A, Bundaberg e Isis-3).

\section{DISCUSSÃO}

Durante um levantamento da incidência de vírus pertencentes ao subgrupo do SCMV no estado de São Paulo (Gonçalves et al., 2004), foi identificado o isolado RIB-1, o qual apresenta características singulares com

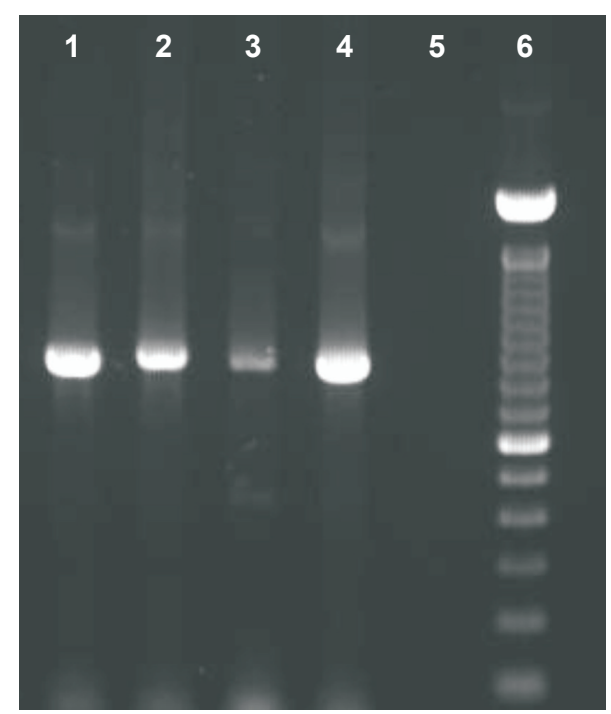

FIG. 4 - Análise eletroforética dos produtos amplificados por RTPCR com os oligonucleotídeos SCMVF4 e SCMVR3, a partir de RNA total extraído de folhas de cana-de-açúcar e sorgo. Colunas 1: isolado RIB-1 ; 2: Isolado JAU-1; 3: isolado PIR-2; 4: sorgo inoculado com isolado RIB-1; 5: sorgo sadio; 6: marcador de DNA $100 \mathrm{bp}$. 


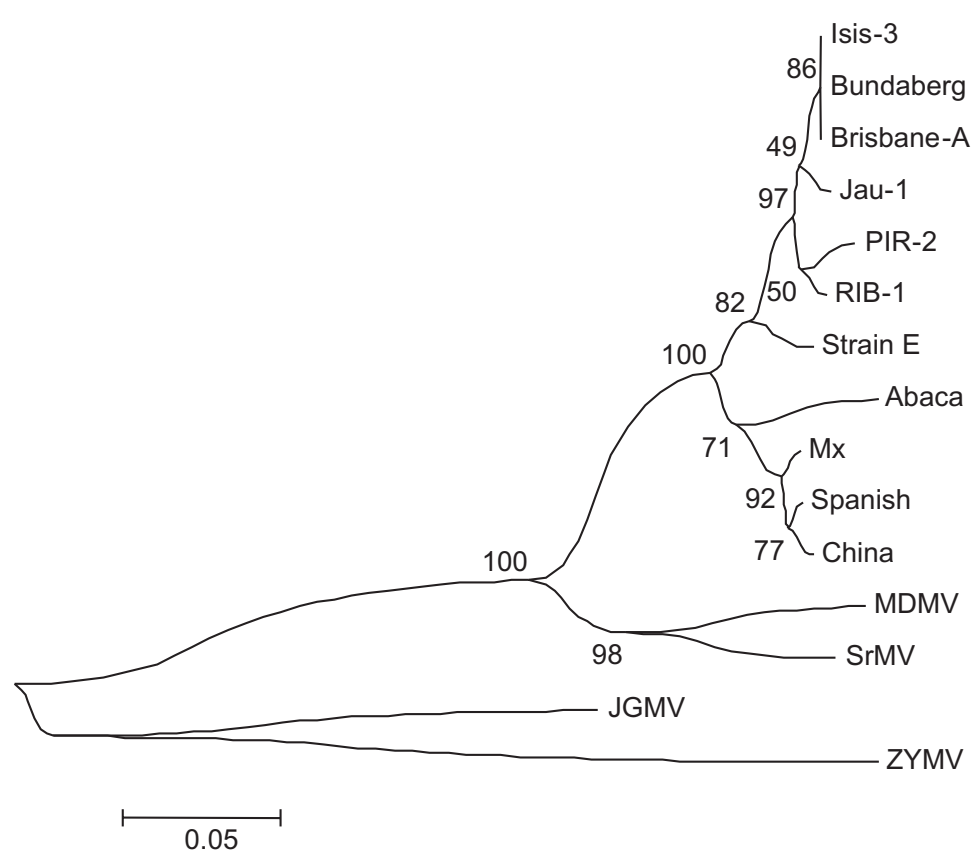

FIG. 5 - Análise filogenética por Neighborjoining empregando as seqüências deduzidas de aminoácidos da proteína capsidial de diferentes isolados do subgrupo do SCMV e espécies de Potyvirus relacionadas. A porcentagem de réplicas de "bootstrap" (2000 repetições) observada é indicada para cada ramo. Abreviações e respectivos números de acesso no GenBank: SCMV RIB-1 (AY819716); SCMV JAU-1 (AY819717), SCMV PIR-2 (AY819718); SCMV Mx (AAO41684); SCMV Bundaberg (AAC17482); SCMV Isis3 (AF006728); SCMV Abaca (AY222743); SCMV Spanish (CAC38364); SMCV Strain E (AAX35329); SCMV Brisbane Strain A (CAC81986); SCMV China (CAC82225); MDMV (CAA04929); SrMV (CAC84434); JGMV (NP619668); ZYMV (out-group) (CAC87636). respeito à sintomatologia e às variedades infectadas no campo. Este isolado também foi encontrado infectando, na mesma lavoura, além de plantas da variedade RB72454, plantas das variedades IAC91-2218 e IAC93-6006, liberadas para cultivo em 2004, e também consideradas tolerantes ao mosaico. Aliada aos sintomas no campo, a caracterização biológica denotou as primeiras evidências de tratar-se de uma nova estirpe do SCMV, devido aos sintomas apresentados pelas hospedeiras diferenciais. Comparativamente aos outros dois isolados, o isolado RIB-1 comportou-se de maneira distinta, provocando mosaico mais severo, coloração avermelhada e necrose do tecido foliar em sorgo "Rio". A infecção e os sintomas de mosaico nessa cultivar indicaram tratar-se de um isolado do subgrupo do SCMV, provavelmente pertencente a uma das espécies, SCMV ou SrMV, que infectam naturalmente a cana-de-açúcar. Por sua vez, a infecção no sorgo TX 2786 descartou a possibilidade de tratar-se da espécie SrMV, que não infecta esta cultivar (Tosic et al., 1990). Apesar dos sintomas apresentados na indicadora para o SCMV, esse isolado não foi detectado em DAS-ELISA com um anti-soro comercial para essa espécie, em contraste com os outros dois isolados testados. No entanto, o isolado RIB-1 foi detectado em PTA-ELISA com o anti-soro policlonal proveniente do Texas, produzido a partir de um "pool" de isolados norte-americanos do SCMV. Esta aparente inconsistência entre os resultados dos testes biológicos e serológicos não é incomum, e a sorologia, muitas vezes, apresentase insatisfatória na identificação de membros da família Potyviridae (Shukla et al., 1992b). As relações antigênicas entre estirpes de uma espécie de Potyviridae, particularmente do gênero Potyvirus, podem ser extremamente complexas e inconsistentes, e freqüentemente relações serológicas não se correlacionam com propriedades biológicas (Koenig, 1988, Van Regenmortel, 2000). Hollings \& Brunt (1981) afirmam que diferentes estirpes de uma mesma espécie de Potyviridae podem ser tão distantemente relacionadas sorologicamente quanto elas são de outras espécies da família. A região Nterminal da proteína capsidial é imunodominante entre os membros da família Potyviridae e, conforme será abordado a seguir, diferenças observadas nessa região podem ser a razão do comportamento sorológico distinto apresentado pelo isolado RIB-1 em relação aos demais isolados. Por sua vez, as observações em MET revelaram a presença de inclusões cilíndricas citoplasmáticas do tipo cata-ventos, "scrolls" e agregados lamelares, cuja ocorrência simultânea é característica de infecção pela espécie SCMV, uma vez que as demais espécies do subgrupo induzem apenas a formação de cata-ventos e "scrolls" (Lesemann et al., 1992). Estes resultados corroboram os relatados na indexação biológica com as hospedeiras diferenciais.

A amplificação dos fragmentos de $888 \mathrm{pb}$, somente com o par de oligonucleotídeos específicos para o SCMV, e os dados de seqüenciamento confirmam que o isolado RIB-1 constitui uma estirpe do SCMV, descartando a possibilidade de tratar-se da espécie SrMV, que permanece sem relato no Brasil até o momento. Apesar do comportamento distinto em relação aos sintomas induzidos em cana-de-açúcar e nas plantas indicadoras, e da ausência de reação cruzada com um anti-soro policlonal comercial, este isolado apresenta alta identidade de nucleotídeos com outras estirpes de SCMV. A região N-terminal da proteína capsidial apresenta maior variabilidade de seqüências entre os membros de Potyviridae, e muitas vezes determina a distinção de estirpes 
e espécies dentro da família (Shukla et al., 1994). Uma possível explicação para essa diversidade é a duplicação de motivos peptídicos curtos, conforme relatado para estirpes do SCMV e SrMV (Frenkel et al., 1991; Yang \& Mirkov, 1997). Quando comparada às seqüências de aminoácidos dos outros dois isolados brasileiros e com as de maior identidade de nucleotídeos depositadas no GenBank (Figura 6), algumas características distinguem a seqüência de aminoácidos da região N-terminal da $\mathrm{CP}$ do isolado RIB-1. Algumas dessas alterações estão presentes, isoladamente, em um dos dois isolados brasileiros. Desta maneira, a presença de um "gap" na posição 44 e a substituição de uma serina por uma alanina na posição 70 , ocorrem apenas no isolado PIR-2. Por sua vez, o isolado JAU-1 compartilha com o RIB-1 a substituição de uma treonina por uma alanina na posição 56. Porém, na posição 59 um ácido aspartâmico aparece no lugar de uma glicina no isolado RIB-1 em relação aos demais isolados alinhados. Os três isolados brasileiros do SCMV apresentam a substituição de um ácido glutâmico por uma alanina na posição 67 , em relação aos demais isolados. Essas características na porção Nterminal da CP podem estar relacionadas, por exemplo, com a ausência de reação com o anti-soro comercial contra a espécie SCMV pelo RIB-1. A mudança de um único aminoácido, ou mesmo de um único nucleotídeo, pode alterar a conformação de uma proteína e as suas propriedades biológicas, conforme demonstrado para mutações no genoma de alguns vírus (Brault et al., 2003; Gonçalves et al., 2005). A análise filogenética apresentada agrupa o RIB-1 com outros isolados menos severos, tanto brasileiros quanto australianos, do SCMV. Todavia, as diferenças observadas na sintomatologia e patogenicidade desse isolado podem estar associadas a outras regiões do genoma dos Potyviridae, como as proteínas P1 e HC-Pro (Revers et al., 1999), não investigadas neste trabalho.

As medidas de controle mais eficientes para o mosaico englobam práticas culturais, como o "roguing" e, principalmente, o uso de variedades resistentes. A eliminação de plantas doentes constitui uma prática economicamente inviável em campos comerciais devido à sua magnitude, porém, é uma medida altamente recomendada em viveiros de propagação de mudas. Por sua vez, os programas de melhoramento genético de cana-de-açúcar visando o desenvolvimento de variedades resistentes ao vírus e a conseqüente eliminação de clones suscetíveis são de extrema importância para evitar o surgimento de novas epidemias da doença. Essas medidas, regularmente adotadas pelo setor canavieiro nacional, têm conseguido controlar de maneira satisfatória a doença no Brasil. Entretanto, o descaso com essas premissas por parte de agricultores desavisados, aliado à ocorrência de novas estirpes do subgrupo do SCMV, têm ocasionado o relato freqüente de novos casos de mosaico no campo. Outra provável contribuição para esse fato advém do plantio do milho na safrinha, expandindo o período de cultivo e conseqüentemente proporcionando um aumento na pressão de inóculo no campo, principalmente no estado de São Paulo, onde cana-de-açúcar e milho muitas vezes são cultivados em áreas vizinhas e em larga escala. $\mathrm{O}$ cultivo dessas culturas em regiões próximas também pode influenciar a taxa de distribuição do mosaico no campo, que por sua vez depende de fatores como: a resistência ou nível de tolerância da variedade de cana-de-açúcar ou milho; estirpe ou estirpes do vírus presentes nessas culturas; número e distribuição dos focos de infecção; número, tipo e atividade de insetos vetores presentes - uma vez que o principal afídeo vetor, $R$. maidis, incide sobre as duas espécies botânicas; e condições climáticas afetando a suscetibilidade das culturas e a atividade e migração dos insetos vetores (Gonçalves, 2002). Levando-se em consideração o quadro descrito acima, as características apresentadas pelo isolado RIB-1, comprovadamente

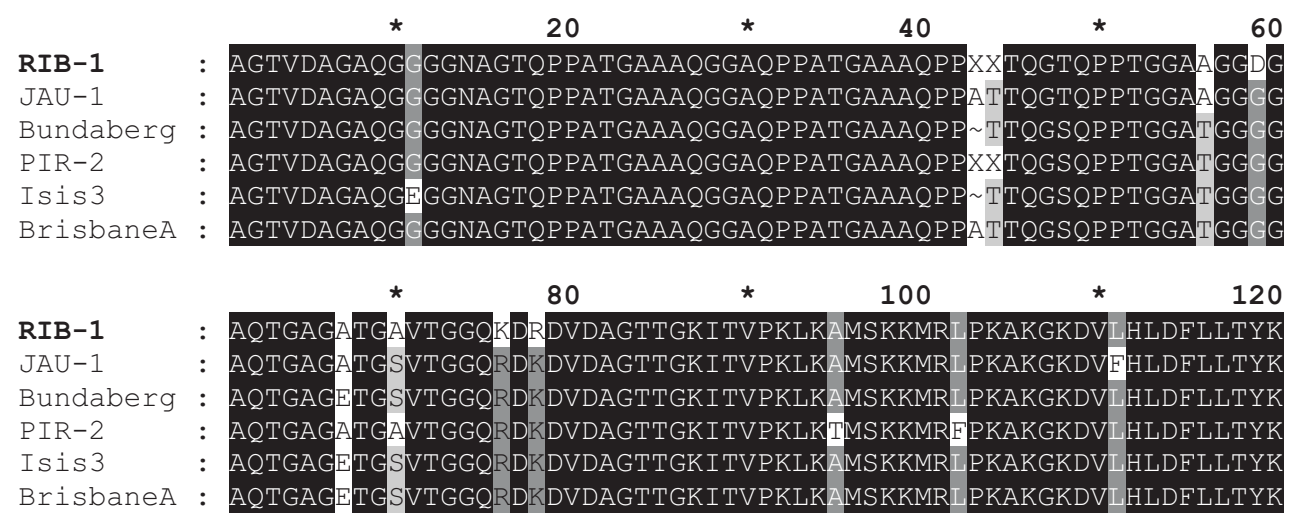

FIG. 6 - Alinhamento da seqüência deduzida de aminoácidos da porção Nterminal da proteína capsidial de diferentes isolados do subgrupo do Sugarcane mosaic virus. Abreviações e respectivos números de acesso no GenBank: SCMV RIB-1 (AY819716); SCMV JAU-1 (AY819717), SCMV Bundaberg (AF006735); SCMV PIR-2 (AY819718); SCMV ISIS-3 (AF006728); SCMV Brisbane-Strain A (AJ278405). 
uma estirpe distinta do SCMV, fazem com que ele deva ser considerado nos testes de avaliação de novos clones e variedades em programas de melhoramento genético de cana-de-açúcar.

\section{AGRADECIMENTOS}

Os autores apresentam seus agradecimentos ao Dr. Marcos G.A. Landell, do Centro de Cana, IAC, e aos Drs. Eugênio C. Ulian e Álvaro Sanguino, e Ms. Marcos V. Casagrande, do Centro de Tecnologia Canavieira, CTC, pelo auxílio técnico e discussão de resultados. Os autores agradecem também ao Dr. Antônio S. Kimus Braz pelo auxílio nas análises filogenéticas e o Dr. Marcelo Eiras pela revisão crítica do manuscrito. Este trabalho foi financiado pelo projeto de Auxílio à Pesquisa FAPESP no 02/03697-8.

\section{REFERÊNCIAS BIBLIOGRÁFICAS}

ALEGRIA, O.M., ROYER, M., BOUSALEM M., CHATENET, M., PETERSCHMITT, M., GIRARD, J-C. \& ROTT, P. Genetic diversity in the coat protein coding region of eighty-six sucarcane mosaic virus isolates from eight countries, particularly from Cameroon and Congo. Archives of Virology 148:357-372. 2003.

BRAULT, V., BERGDOLL, M., MUTTERER, J., PRASAD, V., PFEFFER, S., ERDINGER, M., RICHARDS, K.E. \& ZIEGLERGRAFF, V. Effects of point mutations in the major capsid protein of beet western yellows virus on capsid formation, virus accumulation, and aphid transmission Journal of Virology 77:3247-3256. 2003.

CHAGAS, C., COLARICCIO, A., GALLETI, S.R. \& KITAJIMA, E.W. Infecção natural de Amorphophallus konjac pelo vírus do mosaico do inhame no Brasil. Fitopatologia Brasileira 18:551-554. 1993.

COSTA, A.S., KITAJIMA, E.W. \& ARRUDA, S.C. Moléstias de vírus e de micoplasmas do milho em São Paulo. Revista da Sociedade Brasileira de Fitopatologia 4:39-41. 1971.

DUDIENAS, C., DUARTE, A.P., PATERNIANI, M.E.G.Z., RIBEIRO, J.L., BIANCHINI, M.T., KANTACCH, R.A.D., CASTRO, J.L., SILVEIRA, L.C.P., DENUCCI, S., JUNIOR, J.S., BOLONHESI, D. \& DE SORDI, G. Severidade de doenças no milho safrinha no estado de São Paulo em 1996. Seminário sobre a cultura do milho safrinha. IAC/CDV. Pp. 107-115. 1997.

FAUQUET, C.M., MAYO, M.A., MANILOFF, J., DESSELBERGER, U. \& BALL, L.A. Virus Taxonomy: Eighth Report of the International Committee on Taxonomy of Viruses. London. Academic Press. 2005.

FERNANDES, F.T. \& OLIVEIRA, E. Principais doenças na cultura do milho. Empresa Brasileira de Pesquisa Agropecuária. Circular Técnica n. 26. 1997.

FRENKEL, M.J., JILKA, J.M., MACKERN, N.M., STRIKE, P.M., CLARK JR, J.M., SHUKLA, D.D. \& WARD, D. Unexpected sequence diversity in the amino-terminal ends of the coat proteins of strains of Sugarcane mosaic virus. Journal of General Virology 72:237-242. 1991.
GONÇALVES, M.C., MOREIRA, Y.J.C.B, MAIA, I.G., SANTOS, A.S., FANTIN, G.M., CHAVES, A.L.R., FRANGIONE, D.S.S. \& ULIAN, E.C. Identificação e caracterização de isolados pertencentes ao subgrupo do Sugarcane mosaic virus no estado de São Paulo. Fitopatologia Brasileira 29:129. 2004. (Resumo)

GONÇALVES, M.C., VAN DER WILK, F., DULLEMANS A.M., VERBEEK, M., VEGA, J. \& VAN DEN HEUVEL, J.F.J.M. Aphid Transmission and Buchnera GroEL Affinity of a Potato leafroll virus RTD Deficient Mutant. Fitopatologia Brasileira 30:259-266. 2005.

HALL, T.A. BioEdit: a user-friendly biological sequence alignment editor and analysis program for Windows 95/98/NT. Nucleic Acids Symposium Series 41:95-98. 1999.

HOLLINGS, M. \& BRUNT, A.A. Potyviruses. In: Kurstak, E. (Ed.), Handbook of plant virus infections: Comparative Diagnosis. Amsterdam. Elsevier/North-Holland. pp. 731-807. 1981.

KOENIG, R. Serology and immunochemistry. In: Milne, R.G. (Ed.) The plant viruses: The filamentous plant viruses, Volume 4. New York. Plenum Press. pp. 11-158. 1988.

KOENIG, R. \& PAUL, H.L. Variants of ELISA in plant virus diagnosis. Journal of Virological Methods 5:113-125. 1982.

LESEMANN, D.E., SHUKLA, D.D., TOSIC, M. \& HUTH, W. Differentiation of the four viruses of the sugarcane mosaic virus subgroup based on cytopathology. Archives of Virology (Suppl.) 5:353-361. 1992.

MACKERN, N.M., SHUKLA, D.D., TOLER, R.W., JENSEN, S.G., TOSIC, M., FORD, R.E., LEON, O. \& WARD, C.W. Confirmation that the sugarcane mosaic virus subgroup consists of four distinct potyviruses by using peptide profiles of coat proteins. Phytopathology 81:1025-1029. 1991.

PINTO, N.F.J.A. Comportamento de cultivares de sorgo sacarino em relação ao vírus do mosaico da cana-de-açúcar. Fitopatologia Brasileira 5:438-439. 1980 (Resumo).

PINTO, N.F.J.A. Vírus do mosaico comum da cana-de-açúcar em sorgo (Sorghum bicolor (L.) Moench): Caracterização de isolados, reação de cultivares e herança de resistência. Tese de Doutorado. Piracicaba. ESALQ. 1984.

REVERS, F., LE GALL, O., CANDRESSE, T. \& MAUlE, A.J. New advances in understanding the molecular biology of plant/ potyvirus interactions. Molecular Plant Microbe Interactions 12:367-376. 1999.

SHUKLA, D.D. \& WARD, D. Unexpected sequence diversity in the amino-terminal ends of the coat proteins of strains of Sugarcane mosaic virus. Journal of General Virology 72:237-242. 1991.

SHUKLA, D.D., FRENKEL, M.J., MCKERN, N.M., WARD, C.W., JILKA, J., TOSIC, M. \& FORD, R.E. Present status of the sugarcane mosaic subgroup of potyviruses. Archives of Virology (Suppl.) 5:363-373. 1992a.

SHUKLA, D.D., LAURICELLA, R. \& WARD, C.W. Serology of potyviruses: current problems and some solutions. Archives of Virology (Suppl.) 5:57-69. 1992b.

SHUKLA, D.D., WARD, C.W. \& BRUNT, AA. The Potyviridae. Centre for Agriculture and Biosciences International. Cambridge. Cambridge University Press. 1994.

SEIFERS, D.L., SALOMON, R., MARIE-JEANNE, V., ALLIOT, B., SIGNORET, P., HABER, S., LOBODA, A., ENS, W., SHE, 
Y.M. \& STANDING, K.G. Characterization of a novel potyvirus isolated from maize in Israel. Phytopathology 90:505-513. 2000.

TEAKLE, D.S., SHUKLA, D.D. \& FORD, R.E. Sugarcane mosaic virus. No. 342. In: AAB Descriptions of Plant Viruses. Wellesbourne, Warwick, UK. 1989.

TOSIC, M., FORD, R.E., SHUKLA, D.D. \& JILKA, J. Differentiation of Sugarcane, Maize dwarf, Johnsongrass, and Sorghum mosaic viruses based on reactions of oat and some sorghum cultivars. Plant Disease 74:549-552. 1990.

VAN REGENMORTEL, M.H.V. Introduction to the species concept in virus taxonomy. In: Van Regenmortel, M.H.V., Fauquet, C.M., Bishop, D.H.L., Carstens, E.B., Estes, M.K., Lemon, S.M.,
Maniloff, J., Mayo, M.A., McGeoch, D.J., Pringle, C.R. \& Wickner, R.B. (Eds.) Seventh Report of the International Committee on Taxonomy of Viruses. San Diego. Academic Press. 2000. pp. $3-$ 16.

WAQUIL, J.M., OLIVEIRA, E., PINTO, N.F.J., FERNANDES, F.T. \& CORREAA, L.A. Efeito na produção e incidência de viroses em híbridos comerciais de milho. Fitopatologia Brasileira 21:460463. 1996.

YANG, Z.N. \& MIRKOV, T.E. Sequence and relationships of sugarcane mosaic and sorghum mosaic virus strains and development of RT-PCR-based RFLPs for strain discrimination. Phytopathology 87:932-939. 1997. 